\title{
Characterization of Stone Cleaning by Nd:YAG Lasers with Different Pulse Duration
}

\author{
Laura Bartoli, ${ }^{1}$ Paraskevi Pouli, ${ }^{2}$ Costas Fotakis, ${ }^{2,3}$ Salvatore Siano, ${ }^{1}$ and Renzo Salimbeni ${ }^{1}$ \\ ${ }^{1}$ Istituto di Fisica Applicata "N. Carrara” (IFAC), Consiglio Nazionale delle Ricerche (CNR), Via Madonna del Piano 10, \\ 50019 Sesto Fiorentino (FI), Italy \\ ${ }^{2}$ Institute of Electronic Structure and Lasers (IESL), Foundation for Research and Technology Hellas (FORTH), \\ P.O. Box 1527, 71110 Heraklion, Greece \\ ${ }^{3}$ Department of Physics, University of Crete, 71003 Heraklion, Greece
}

Received 15 September 2006; Revised 15 December 2006; Accepted 27 December 2006

Recommended by Wolfgang Kautek

The present work is a comparative study on the laser cleaning of stonework using Nd:YAG lasers at different pulse durations. The ablation rate, the degree of cleaning, and the appearance of the treated surface were studied irradiating a simulated sample and a real stone artefact using three different Nd:YAG laser systems with pulse duration of 90 microseconds, 15 nanoseconds, and 150 picoseconds. To our knowledge, the picosecond laser is here used for the first time in stone conservation. Differences in efficiency and in cleaning result are shown and discussed.

Copyright (c) 2006 Laura Bartoli et al. This is an open access article distributed under the Creative Commons Attribution License, which permits unrestricted use, distribution, and reproduction in any medium, provided the original work is properly cited.

\section{INTRODUCTION}

The use of Nd:YAG lasers as a cleaning tool for the removal of black pollution encrustation from a variety of stonework is well known, as reported in restoration studies. Nevertheless, so far, there has not been a general agreement about the best choice of laser pulse duration.

Up to a few years ago, laser cleaning of stones was mainly carried out using nanosecond (ns) pulse Q-switched (QS) Nd:YAG lasers but several research groups documented problems connected with the aggressiveness [1,2] and the yellow appearance that QS lasers can induce on certain lithotypes [3-5]. Many technological solutions have been provided to solve the mentioned problems. In particular, the use of short free running (SFR) Nd:YAG laser systems has been proposed [2] to overcome mainly the lack of choice and the aggressiveness of QS laser on fragile stones and to avoid the yellowing of the substrate after the cleaning. In addition, a new class of fiber-coupled long Q-switched laser (LQS), with variable pulse duration from tens to hundreds of ns, has been recently used for the cleaning of metal artworks as well as for stone cleaning with satisfactory results [6].

Recently, the ultra-short laser technology was employed in various material processing applications. Studies have shown that the use of shorter pulse-widths is associated with minimal thermal and chemical induced alterations, while ensuring high spatial confinement and control [7-10]. Initial studies on the use of ultra-short laser pulses in the processing and analysis of objects with cultural and historical importance [11] have shown their unique advantages (minimal photochemical modifications to the remaining material and high precision nearly independent of the optical properties of the substrate) and thus highlight the prospective of their exploitation in demanding applications. This work attempts to assess their viability in stonework conservation and, to our knowledge, the picosecond (ps) regime is here studied for the first time for the laser cleaning of pollution encrustations.

\section{EXPERIMENT}

In this paper, the pulse duration effect on the laser assisted removal of pollution crusts on stonework is investigated. Laser cleaning tests with three Nd:YAG laser systems emitting infrared pulses $(1064 \mathrm{~nm})$ at different pulse duration $(\mu \mathrm{s}, \mathrm{ns}$, ps) were performed on both real black crusts on marble as well as on a reference sample with simulated thick crust. The cleaning result was comparatively assessed on the basis of the removal efficiency (etching rate) and the cleaning result (morphology and coloration of the laser cleaned surfaces). 


\section{MATERIAL AND METHODS}

Three Nd:YAG laser systems at their fundamental wavelength $(1064 \mathrm{~nm})$ were used in the present study:

(1) a fiber-coupled SFR laser (El.En. EOS 1000) with a variable pulse duration between $50-130 \mu$ s for increasing output energies in the range of 120 up to $1000 \mathrm{~mJ} /$ pulse,

(2) a Q-switched system (SPECTRON SL805) emitting pulses of $15 \mathrm{~ns}$ and maximum output energy of $450 \mathrm{~mJ}$, and

(3) a Q-switched system (EKPLA SL 312M) with pulses up to $120 \mathrm{~mJ}$ and $150 \mathrm{ps}$ duration.

A reference sample simulating thick crust on stone (sample S) was used for comparison purposes. For the encrustation simulation the idea was to imitate the most common accumulation encountered on archaeological objects both in terms of composition and morphology. Therefore, it was attempted to adhere a mixture of pulverised encrustation (collected from real archaeological objects) on marble plates using gypsum as the binding medium. The composition of the layer is as follows: $49.25 \mathrm{wt} \%$ of pulverised encrustation from real excavation objects and $49.25 \mathrm{wt} \%$ of hydrated calcium sulphate $\left(\mathrm{CaSO}_{4} 2 \mathrm{H}_{2} \mathrm{O}\right)$. To enhance the colour of the mixture and imitate the real case, ferrous oxide $\left(\mathrm{Fe}_{2} \mathrm{O}_{3}\right)$ and carbon $(\mathrm{C})$ were added in very small quantities ( 0.50 and $1.00 \mathrm{wt} \%$, resp.). XRD analysis on the pulverised encrustation indicated the following components: sodium sulphate $\left(\mathrm{Na}_{2} \mathrm{SO}_{4}\right)$, magnesium sulphate hydrate $\left(\mathrm{MgSO}_{4} 6\left(\mathrm{H}_{2} \mathrm{O}\right)\right)$, picromerite $\left(\mathrm{K}_{2} \mathrm{Mg}\left(\mathrm{SO}_{4}\right)_{2} 6 \mathrm{H}_{2} \mathrm{O}\right)$, syngenite $\left(\mathrm{K}_{2} \mathrm{Ca}\left(\mathrm{SO}_{4}\right)_{2} \mathrm{H}_{2} \mathrm{O}\right)$, gypsum $\left(\mathrm{CaSO}_{4}, 2 \mathrm{H}_{2} \mathrm{O}\right)$ and calcium carbonate $\left(\mathrm{CaCO}_{3}\right)$. The above mixture was applied wet by brushing in several layers on the freshly cut marble tablets in order to obtain a maximum thickness of about $1.5 \mathrm{~mm}$.

For the characterization study, some fragments coming from a tortile column from Florence's cathedral (samples R) were selected. The composition and morphology of the black encrustation accumulated on the surface as well as the stratigraphy of the various layers and the decision of the cleaning limit on these fragments are discussed in previous studies $[6,12]$.

The ablation trials were performed both in dry and wet (water-assisted) conditions. The laser spot was maintained constant throughout the tests, while the fluence variation was achieved using the appropriate optical attenuators. Etch depth measurements, performed after laser ablation, were carried out using a mechanical stylus profilometer (Perthometer S5P, Mahr). Scanning electron microscopy (SEM) observations were performed with a Quanta FEI 200 instrument.

\section{RESULTS AND DISCUSSION}

\subsection{Ablation rates}

Figure 1 displays the ablation rate curves attained for the artificial samples. The measurements were performed both in

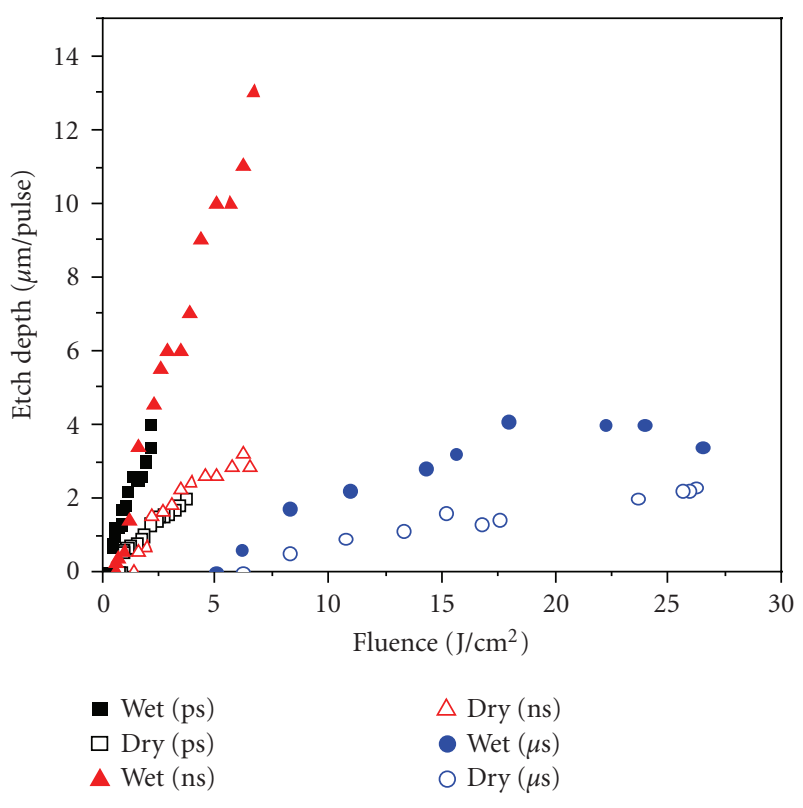

FIGURE 1: Ablation rate curves obtained for the artificial sample using Nd:YAG laser pulses at $1064 \mathrm{~nm}$ at three different pulse duration regimes.

dry and wet conditions. The behavior of the ablation rates is similar to the typical one of thermal ablation, which is characterized by a threshold fluence $F_{\text {th }}$, a linear regime and, in some cases, a saturation fluence $F_{s}$.

From the observation of the different curves, it is noticed that, regardless the pulse duration, the ablation in wet conditions is more efficient than in the dry ones. Water penetrates into the black crust's pores and the fast heating of the liquid film, due to the absorption of energy from the laser pulse, leads to an explosive vaporisation of the water molecules. This explosion generates additional forces within the encrustation which make the ejection of the dirt particles more effective [13].

From the graph it can be also derived that the etching process is more efficient, at equal fluences, for shorter pulse lengths. The shorter the pulse duration, $t_{L}$, the shorter the thermal diffusion length $2 \sqrt{D t_{L}}$ in the substrate, where $D$ is the material diffusivity. This means that with shorter pulses less energy is needed to reach the explosive vaporisation. On the other side, the slope of ablation curves associated to shorter pulses is steeper and this behavior leads to a less controllable cleaning process because a small increasing of fluence values results in a higher difference in material removal.

Another important result deals with the ablation threshold, which plays a fundamental role in the optimisation of the cleaning process. From Figure 1 and from the detail of Figure 2, it can be noticed that the ablation threshold increases with increasing pulse duration and thus higher fluence values are required when cleaning with longer pulsewidths.

The experimental threshold values are shown in Table 1. 


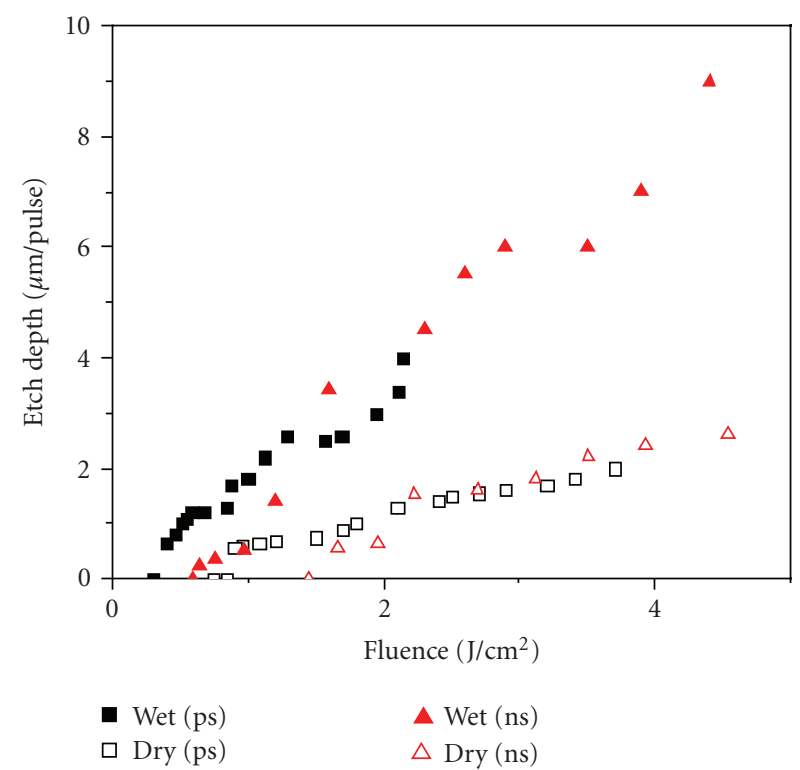

FIgURe 2: Detail of the ablation curves for the ns and ps regimes for Sample S.

TABLE 1: Experimental threshold fluence values as derived from the measurements on the artificial sample.

\begin{tabular}{l|cc}
\hline Pulse duration & Conditions & $F_{\text {th }}\left(\mathrm{J} / \mathrm{cm}^{2}\right)$ \\
\hline $90 \mu \mathrm{s}$ & Wet & 5.0 \\
$90 \mu \mathrm{s}$ & Dry & 6.2 \\
$15 \mathrm{~ns}$ & Wet & 0.6 \\
$15 \mathrm{~ns}$ & Dry & 1.4 \\
$150 \mathrm{ps}$ & Wet & 0.3 \\
$150 \mathrm{ps}$ & Dry & 0.8 \\
\hline
\end{tabular}

In Figure 2, a detail of the curves for the picosecond and nanosecond regimes is displayed. For low fluences, close to the ablation threshold, it seems that the ps pulses remove more material than the ns ones (especially in wet conditions) but, after a critical point $\left(\sim 1.6 \mathrm{~J} / \mathrm{cm}^{2}\right.$ for both wet and dry irradiation), where the two curves are crossing, the removal rate is more or less the same.

Figure 3 displays the ablation rate curves obtained for the real black crust (Sample R). The measurements have been performed both in dry and wet conditions. The behavior of the curves is similar to that attained for the simulation samples.

From the observation of the different curves, it is noticed that, for the real crust too, the ablation in wet conditions is more efficient than in the dry ones. The increasing of the ablation threshold with the pulse duration is still present and the cleaning efficiency is higher for shorter pulse durations. The experimental threshold values are reported in Table 2.

A close inspection of the ps and ns ablation curves is displayed in Figure 4.

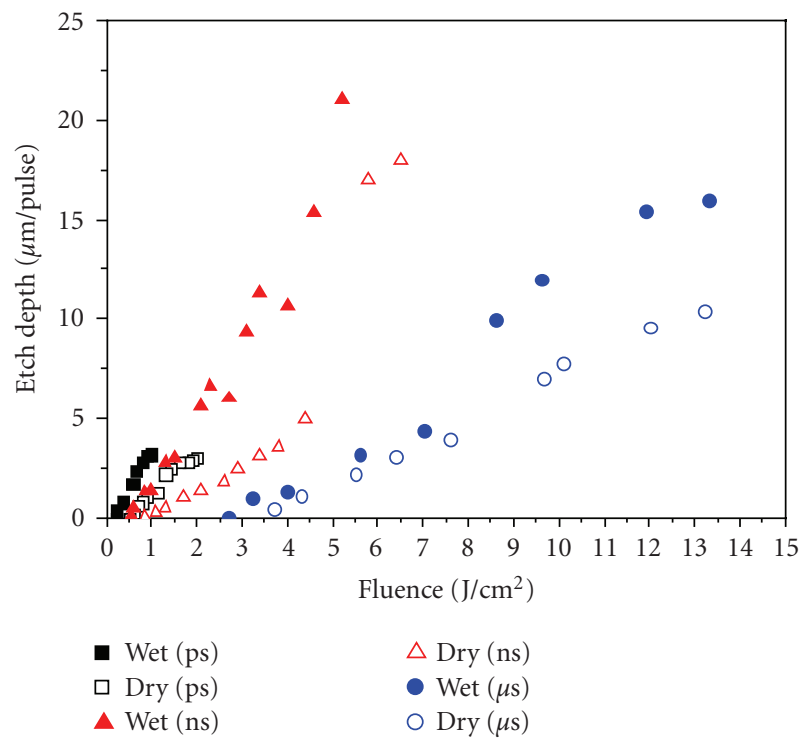

Figure 3: Ablation rate curves obtained for the real black crust (Sample R) using Nd:YAG laser pulses at $1064 \mathrm{~nm}$ at three different pulse duration regimes.

TABLE 2: Experimental threshold fluence values as derived from the measurements on the real crust.

\begin{tabular}{l|cc}
\hline Pulse duration & Conditions & $F_{\text {th }}\left(\mathrm{J} / \mathrm{cm}^{2}\right)$ \\
\hline $90 \mu \mathrm{s}$ & Wet & 2.70 \\
$90 \mu \mathrm{s}$ & dry & 3.50 \\
$15 \mathrm{~ns}$ & Wet & 0.56 \\
$15 \mathrm{~ns}$ & dry & 0.86 \\
$150 \mathrm{ps}$ & Wet & 0.20 \\
$150 \mathrm{ps}$ & Dry & 0.50 \\
\hline
\end{tabular}

From Figure 4, it is clear that for low fluence values, close to the ablation threshold, ps pulses are, as expected, more efficient to remove the crust material both in wet and dry conditions. Unfortunately for this specific sample, composition and morphology of encrustation etch depth studies in the ps regime were stopped at $2 \mathrm{~J} / \mathrm{cm}^{2}$ (dry condition) and $1.5 \mathrm{~J} / \mathrm{cm}^{2}$ (wet condition) because, above these values, the underlying sample surface was starting to get visibly damaged. As a result, it is not possible to compare the ablation efficiency of ps and ns regimes for higher fluence values.

Comparing the etch depth attained for the artificial sample and for the real crust it is shown that, at the same fluence and for the same pulse duration and irradiation conditions, a larger amount of material is removed in the real black crust. The corresponding etch depths obtained for fluence values of about $1 \mathrm{~J} / \mathrm{cm}^{2}$ for ps and ns pulses both in wet and dry conditions are presented in Table 3. It should be taken into account that the real black crust is quite heterogeneous, both in thickness and in consistency and appears "softer" than the artificial crust. 


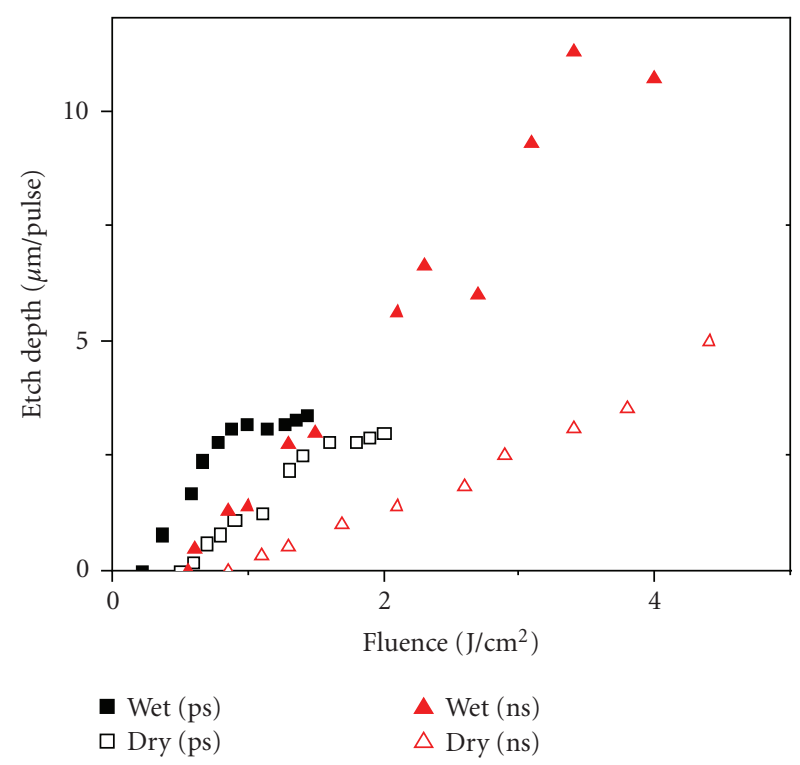

FIgURE 4: Detail of the ablation curves for the ns and ps regimes for Sample R.

TABLE 3: Comparative etch depth values for the simulation (S) and the real (R) encrustation for fluence values of about $1 \mathrm{~J} / \mathrm{cm}^{2}$, in ps and ns cleaning regime for wet and dry irradiation conditions.

\begin{tabular}{l|ccc}
\hline Pulse duration & Conditions & Sample & $\begin{array}{c}\text { Etch depth } \\
(\mu \mathrm{m} / \text { pulse })\end{array}$ \\
\hline $150 \mathrm{ps}$ & Wet & $\mathrm{S}$ & 1.8 \\
$150 \mathrm{ps}$ & Wet & $\mathrm{R}$ & 3.2 \\
$15 \mathrm{~ns}$ & Wet & $\mathrm{S}$ & 0.5 \\
$15 \mathrm{~ns}$ & Wet & $\mathrm{R}$ & 1.4 \\
$150 \mathrm{ps}$ & Dry & $\mathrm{S}$ & 0.6 \\
$150 \mathrm{ps}$ & Dry & $\mathrm{R}$ & 1.25 \\
$15 \mathrm{~ns}$ & Dry & $\mathrm{S}$ & $\begin{array}{c}\text { No ablation } \\
\end{array}$ \\
$15 \mathrm{~ns}$ & Dry & $\mathrm{R}$ & 0.3 \\
\hline
\end{tabular}

\section{The cleaning problem}

The stratigraphy of the tortile column is shown in Figure 5 [6]. From the outer to the inner layers, black crust, sulphated Ca-oxalate film, and surface pseudomorphic sulphation can be observed. The Ca-oxalate film includes a pigment load formed by ochres and black carbon. Cleaning trials were performed on the column using the three different laser systems in wet conditions. The fluence values used were as follow:

(i) $3.9 \mathrm{~J} / \mathrm{cm}^{2}$ and $9 \mathrm{~J} / \mathrm{cm}^{2}$ at $90 \mu \mathrm{s}$,

(ii) $0.85 \mathrm{~J} / \mathrm{cm}^{2}$ and $1.4 \mathrm{~J} / \mathrm{cm}^{2}$ at $15 \mathrm{~ns}$, and

(iii) $0.55 \mathrm{~J} / \mathrm{cm}^{2}$ at $150 \mathrm{ps}$,

corresponding to values just above and well above the threshold values for each laser as measured through this study.
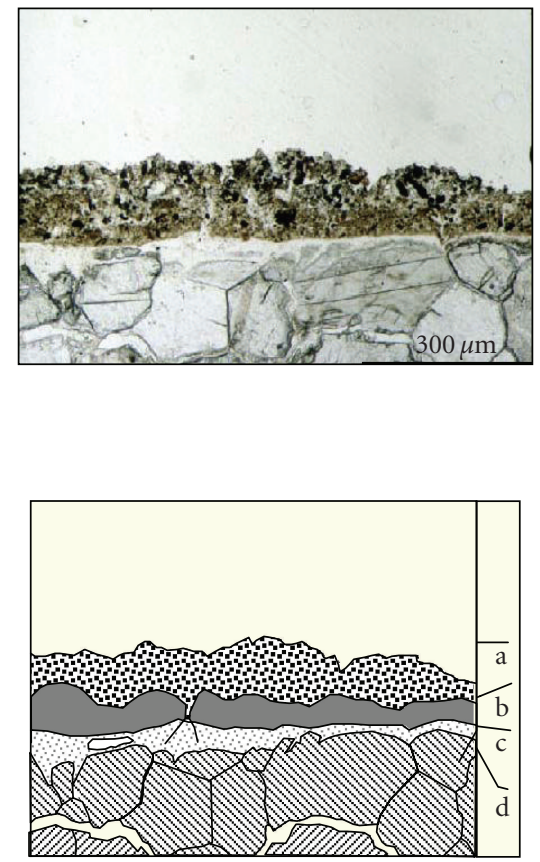

Figure 5: Stratigraphy of the tortile column. (a) Black crust, (b) Caoxalate film, (c) surface pseudomorphic sulphation, (d) substrate. The scale bar is $300 \mu \mathrm{m}$.

In Figure 6, three SEM images of the surface after cleaning with the three lasers are displayed.

In every case, the surface appears quite smooth and there is no evidence of mechanical damages. To the naked eye, very small colour differences were observed in the three different treated parts. The cleaning result is satisfactory in all conditions, taking into account the deteriorated state of the original surface of the column, which was most probably weathered before the black crust was deposited.

\subsection{Degree of cleaning}

In Figure 7, the stratigraphies of the treated parts are displayed, showing the final cleaning level achieved on the column using the three different laser systems.

The black crust was completely removed in all cases. The main differences among the three stratigraphies lay in the degree of removal of the Ca-oxalate layer and in the roughness of the cleaned surface. The surfaces treated with the different lasers appear smooth and the cleaning results effective but careful (Figures $7(a)-7(c)$ ). In the area cleaned with the SFR- $\mu$ s laser, the Ca-oxalate layer is clearly preserved (see, Figure $7(\mathrm{a})$ ). The final surface is smooth and very homogeneous.

On the other hand, throughout this study, shorter pulsewidths did not result in similar cleaning effect as regards the $\mathrm{Ca}$-oxalate layer. This result is under further investigation as it has often been reported in the literature that Ca-oxalate layers have been successfully preserved using Q-switched 


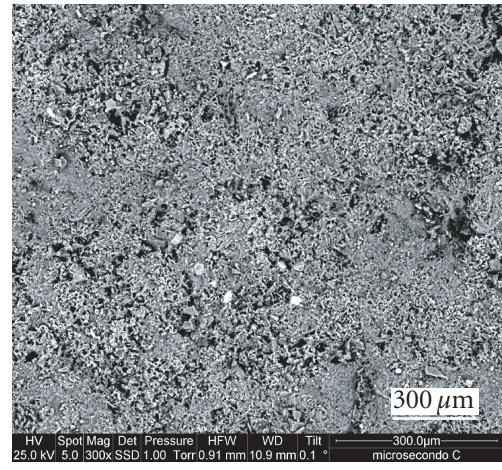

(a)

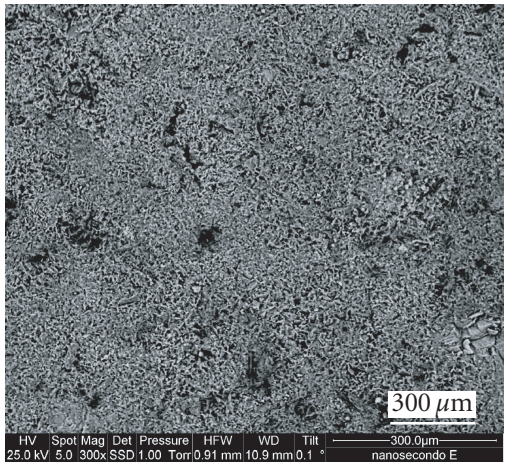

(b)

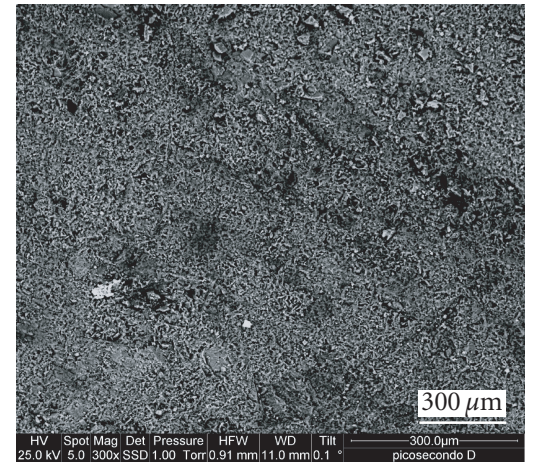

(c)

FIGURE 6: SEM pictures of the treated surface. (a) $90 \mu \mathrm{s}\left(F_{L}=3.9 \mathrm{~J} / \mathrm{cm}^{2}\right)$, (b) $15 \mathrm{~ns}\left(F_{L}=1.4 \mathrm{~J} / \mathrm{cm}^{2}\right)$, and $(\mathrm{c}) 150 \mathrm{ps}\left(F_{L}=0.54 \mathrm{~J} / \mathrm{cm}^{2}\right)$.

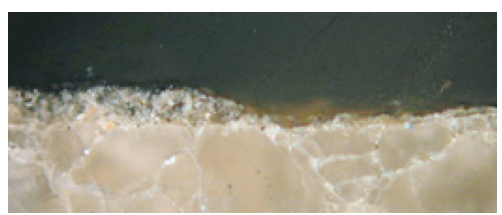

(a)

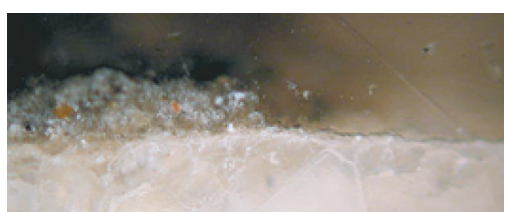

(b)

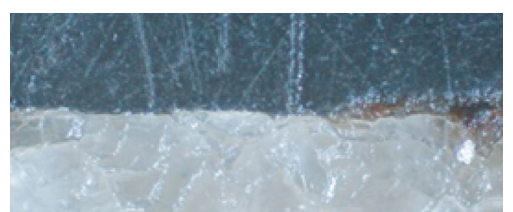

(c)

FIGURE 7: Stratigraphies of the treated parts on sample R. (a) $90 \mu \mathrm{s}\left(F_{L}=3.9 \mathrm{~J} / \mathrm{cm}^{2}\right)$, (b) $15 \mathrm{~ns}\left(F_{L}=0.85 \mathrm{~J} / \mathrm{cm}^{2}\right),(\mathrm{c}) 150 \mathrm{ps}\left(F_{L}=0.54 \mathrm{~J} / \mathrm{cm}^{2}\right)$ (10× magnification).

Nd:YAG lasers in the ns regime, including the laser cleaning of the Parthenon West Frieze. The "ancient monochromatic surface layers," rich in Ca-oxalates, which uniquely characterize the sculpted surface of the Frieze were perfectly preserved during laser cleaning, using QS-ns pulses at $1064 \mathrm{~nm}$ in the range of $0.5-0.8 \mathrm{~J} / \mathrm{cm}^{2}$ [14]. This may be explained by the fact that the original surface of the column was deteriorated and in several areas the black crust was formed on already weathered surface. As it is very difficult to discern the existence of the Ca-oxalate layers beneath the thick black crust prior to cleaning, it may be possible that the comparative studies were performed on areas where Ca-oxalate layers were not uniformly preserved. Therefore, further studies must be undertaken to prove the initial experiments.

It is worth noticing that in the case of ns cleaning the fluence window to eliminate this kind of encrustation is very small: the use of a slightly higher fluence $\left(F_{L}=1.4 \mathrm{~J} / \mathrm{cm}^{2}\right)$ caused, indeed, an unacceptable etching of the marble substrate (Figure 8(a)). In contrast, laser cleaning trials in the $\mu$ s regime at fluence values significantly higher than the threshold $\left(9.0 \mathrm{~J} / \mathrm{cm}^{2}\right.$, about three times the threshold value) did not cause any damage to the substrate, including the Ca-oxalate layers (Figure 8(b)). Therefore, it can be said that the "safe" fluence window for longer pulse durations is significantly bigger, allowing more flexibility to the operator and less possibilities to cause side effects on the original stone surface.

\section{CONCLUSIONS}

This work provides a characterization of the effects involved in laser cleaning of stonework under different operative conditions. Three Nd:YAG laser systems have been used having various pulse durations: $150 \mathrm{ps}, 15 \mathrm{~ns}, 90 \mu \mathrm{s}$. The differences among ablation rates in dry and wet conditions, the degree of cleaning, and the appearance of the treated surface were characterized by using simulation samples and a stone artefact exposed outdoors. It was shown that, regardless the pulse duration, the cleaning in wet condition is more efficient than the dry one. In addition, the etching is more efficient, at equal fluences, for shorter pulse lengths. The ps laser, which was used here for the first time in cleaning of pollution crusts from stonework, did not cause any mechanical damage to the treated surface, but the fluence has to be kept quite low. The QS-ns laser was very effective in the removal of the black crust but the operative fluence window is very small: it is necessary to use a low fluence, very close to the threshold one, to avoid mechanical damages to the substrate. The SFR$\mu$ s laser, which was specifically designed for the cleaning of stonework, did not cause any thermal or mechanical damage to the surface even at high fluences. Throughout this study, the Ca-oxalate layer was better preserved with the SFR$\mu$ s laser and further studies are underway to confirm this 


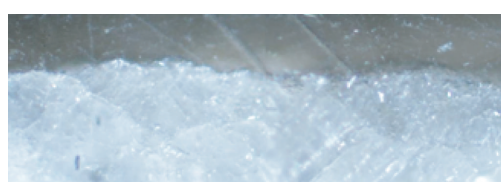

(a)

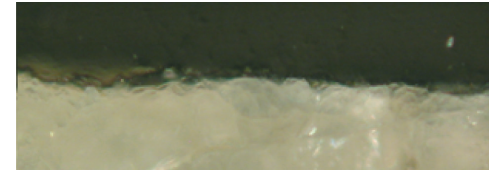

(b)

FIGURE 8: Stratigraphies of the treated parts on sample R. (a) $15 \mathrm{~ns}\left(F_{L}=1.4 \mathrm{~J} / \mathrm{cm}^{2}\right)$, (b) $90 \mu \mathrm{s}\left(F_{L}=9.0 \mathrm{~J} / \mathrm{cm}^{2}\right)(20 \times \mathrm{magnification})$.

result and explain the mechanisms that may influence such behavior.

\section{ACKNOWLEDGMENTS}

The first author acknowledges support from the "ATHENA" EST Marie Curie project (MEST-CT-2004-504067) at IESLFORTH. The authors would also like to thank G. Doganis and A. Galanos (Lithou Sintirissis Inc. Conservation Associates, Athens, Greece) for fruitful discussions on the morphology and simulation of stonework encrustations and for the preparation of the reference samples with simulated crust.

\section{REFERENCES}

[1] M. S. D’Urbano, C. Giovannone, P. Governale, A. Pandolfi, and U. Santamaria, "A standardized methodology to check the effects of laser cleaning of stone surfaces," in Proceedings of the 3rd International Symposium on the Conservation of Monuments in the Mediterranean Basin, V. Fassina, H. Ott, and F. Zezza, Eds., pp. 955-962, Venice, Italy, 1994.

[2] S. Siano, F. Margheri, P. Mazzinghi, et al., "Laser ablation in the artworks restoration: benefits and problems," in Proceedings of International Conference on Lasers, vol. 18, pp. 441-444, Charleston, SC, USA, December 1995.

[3] P. Bromblet, M. Labouré, and G. Orial, "Diversity of the cleaning procedures including laser for the restoration of carved portals in France over the last 10 years," Journal of Cultural Heritage, vol. 4, supplement 1, pp. 17-26, 2003.

[4] V. Vergès-Belmin and C. Dignard, "Laser yellowing: myth or reality?" Journal of Cultural Heritage, vol. 4, supplement 1, pp. 238-244, 2003.

[5] G. Marakis, P. Pouli, V. Zafiropulos, and P. MaravelakiKalaitzaki, "Comparative study on the application of the 1st and the 3rd harmonic of a Q-switched Nd:YAG laser system to clean black encrustation on marble," Journal of Cultural Heritage, vol. 4, supplement 1, pp. 83-91, 2003.

[6] S. Siano, R. Salimbeni, A. Mencaglia, et al., "Phenomenological characterisation of stone cleaning by different laser pulse duration and wavelength," in Proceedings of the 6th International Congress on Lasers in the Conservation of Artworks (LACONA VI '05), Vienna, Austria, September 2005.

[7] D. Bäuerle, Laser Processing and Chemistry, Springer, Berlin, Germany, 2000.

[8] S. Küper and M. Stuke, "Ablation of polytetrafluoroethylene (Teflon) with femtosecond UV excimer laser pulses," Applied Physics Letters, vol. 54, no. 1, pp. 4-6, 1988.

[9] J. K. Frisoli, Y. Hefetz, and T. F. Deutsch, "Time-resolved UV absorption of polyimide. Implications for laser ablation," Applied Physics B, vol. 52, no. 3, pp. 168-172, 1991.
[10] S. Küper and M. Stuke, "Femtosecond UV excimer laser ablation," Applied Physics B, vol. 44, no. 4, pp. 199-204, 1987.

[11] P. Pouli, G. Bounos, S. Georgiou, and C. Fotakis, "Femtosecond laser cleaning of painted artefacts; is this the way forward?" in Proceedings of the 6th International Congress on Lasers in the Conservation of Artworks (LACONA VI '05), Vienna, Austria, September 2005.

[12] R. Salimbeni, R. Pini, and S. Siano, "Achievement of optimum laser cleaning in the restoration of artworks: expected improvements by on-line optical diagnostics," Spectrochimica Acta-Part B: Atomic Spectroscopy, vol. 56, no. 6, pp. 877-885, 2001.

[13] M. Cooper, Laser Cleaning in Conservation: An Introduction, Butterworth Heinemann, Oxford, UK, 1998.

[14] P. Pouli, K. Frantzikinaki, E. Papakonstantinou, V. Zafiropulos, and C. Fotakis, "Pollution encrustation removal by means of combined ultraviolet and infrared laser radiation: the application of this innovative methodology on the surface of the Parthenon West Frieze," in Proceedings of the 5th International Congress on Lasers in the Conservation of Artworks (LACONA V'03), K. Dickmann, C. Fotakis, and J. F. Asmus, Eds., vol. 100 of Springer Proceedings in Physics, pp. 333-340, Osnabrueck, Germany, September 2003. 